\title{
Psychological Counseling in Universities under New Normal Goals
}

\author{
Chang Xiangwei \\ Henan Polytechnic Institute,Nanyang, Henan, China
}

\begin{abstract}
:
Based on the investigation of College Students' psychological problems and the analysis of College Students' psychological status, this paper designs and develops a college students' psychological counseling support system according to the relevant theories and methods of psychological counseling. The system has a variety of forms of psychological counseling. Through peer chat rooms, language, text, music and other media, it can guide, help and inspire the psychological problems of the helpers, so as to alleviate the psychological tension and conflict of the helpers. The results show that emergency source can change the cognition, emotion, attitude and behavior of College students so that it can better adapt to the university environment and keep healthy.
\end{abstract}

Keywords: College Students, Psychological Counseling, Support System.

\section{INTRODUCTION}

The realization of the great rejuvenation of the Chinese nation needs to cultivate highquality college students suitable for modernization and make them become the pillars of our country [1-2]. Good psychological quality is an important part of College Students' overall quality. College students are at the peak of physical and mental development. With the development of physiology and psychology, the increase of competitive pressure, the increase of social experience and the change of thinking mode, they will encounter or produce various psychological problems in learning, life, employment, interpersonal communication and selfconsciousness [3]. If not solved in time, it will have a negative impact on the healthy growth of students, and serious psychological problems will make students have behavior disorders or personality defects [4-5].

China pays more and more attention to the mental health education of college students. The spirit of the notice document of the basic construction standards for students' mental health education in Colleges and universities (Trial) issued by the general office of the Ministry of education requires colleges and universities to pay attention to students' mental health education 
Article History: Received: 28 October 2021 Revised: 05 December 2021 Accepted: 10 January 2022 Publication: 28 February 2022

[6]. The issuance of the document spirit of the Ministry of education reflects the severe current situation of College Students' psychological problems in China, which requires colleges and universities to strengthen college students' mental health education and build a complete college students' psychological counseling room [7-9]. The problems that conventional mental health education can not meet urgently need to be solved by new network technology and establishing a perfect psychological counseling support system.

\section{SYSTEM ANALYSIS AND DESIGN}

1.Investigation and demand analysis of psychological problems

College Students' psychological counseling support system is to use various forms to provide psychological counseling to the helpers through voice, text, music, reading and other ways, and alleviate the psychological tension and conflict of the visitors through "conversation counseling", so as to eliminate the misunderstanding of psychological counseling. And make it change in behavior, cognition, emotion, evaluation and belief, so as to better adapt to the school living environment and maintain physical and mental health [10].

The popularization of psychological knowledge and how to deal with psychological problems urgently need to be solved by education departments and universities for students. Psychological crisis events occur frequently. It has become an important task to understand the attitude of college students seeking professional psychological help and take effective measures to maintain college students' mental health. A network counseling psychological system is ready to come out. Based on the above questions, we now conduct a survey on the psychological status of college students. The survey sample is 100 people randomly selected and answered on the spot in giant square of Shanxi Normal University. 89 valid questionnaires were recovered. The survey contents are shown in Table 1.

TABLE I. Investigation on psychological problems of College Students

\begin{tabular}{|c|c|}
\hline $\begin{array}{c}\text { INVESTIGATION } \\
\text { CONTENT }\end{array}$ & SURVEY OPTIONS \\
\hline $\begin{array}{c}\text { WHAT DO YOU THINK IS } \\
\text { THE REASON TO SEE A } \\
\text { PSYCHOLOGIST? }\end{array}$ & $\begin{array}{c}\text { A. Mental problems B. Psychological confusion C. Very } \\
\text { normal }\end{array}$ \\
\hline $\begin{array}{c}\text { HAVE YOU EVER HAD } \\
\text { PSYCHOLOGICAL } \\
\text { CONFUSION? }\end{array}$ & A.Yes B.No \\
\hline DO YOU THINK A & PSYCHOLOGY TEACHER \\
CAN SOLVE YOUR & A.Yes, B. Basically yes C. No \\
\hline
\end{tabular}


Article History: Received: 28 October 2021 Revised: 05 December 2021 Accepted: 10 January 2022 Publication: 28 February 2022

\begin{tabular}{|c|c|}
\hline PROBLEM? & \\
\hline $\begin{array}{l}\text { DO YOU UNDERSTAND } \\
\text { PEER COUNSELING? }\end{array}$ & A. Know B. Heard C. Don't know at all \\
\hline $\begin{array}{c}\text { WHO DO YOU CHOOSE } \\
\text { TO TALK TO WHEN YOU } \\
\text { ENCOUNTER } \\
\text { PSYCHOLOGICAL } \\
\text { CONFUSION? }\end{array}$ & $\begin{array}{l}\text { A. Family B.Dormitory chief C.Teacher D.Psychological } \\
\text { counselor E.Bosom friend F.Others }\end{array}$ \\
\hline $\begin{array}{l}\text { HOW DO YOU FEEL } \\
\text { ABOUT NETWORK PEER } \\
\text { CONSULTATION? }\end{array}$ & $\begin{array}{l}\text { A. Well solved the problem of face-to-face. You can open } \\
\text { your heart B. You can try C.No, you can't solve the } \\
\text { problem }\end{array}$ \\
\hline $\begin{array}{c}\text { UNDER WHAT } \\
\text { CIRCUMSTANCES } \\
\text { SHOULD I GO TO A } \\
\text { PSYCHOLOGICAL } \\
\text { TEACHER? }\end{array}$ & A. I don't know. B.Go again when you're going crazy \\
\hline
\end{tabular}

\section{System design}

College Students' psychological counseling support system is designed and developed based on B / S (Browser / server) mode. The user types are divided into ordinary users, peer consultants, tourists and system administrators, all of which can access the server through the web browser page. The whole system application adopts a three-tier architecture, which logically divides the system into presentation layer, business layer and data layer.

The presentation layer representative provides users with the overall interface of the system. Different users can carry out relevant operations. For example, when ordinary members log in, they will make an authentication request to the business layer. The business layer will verify with the data layer. When the comparison results are consistent, ordinary members will log in successfully. The three levels cooperate with each other to ensure the normal operation of the system.

The flow chart clearly describes the execution sequence of each module of the system, making the operation steps more clear, so as to achieve the use effect of the system.

When users browse the system as tourists, they can choose to register members. If they do not register members, they can go to the psychological test module for psychological test as tourists, listen to music in the music counseling module, or read inspirational articles in the reading module, so as to popularize mental health knowledge and prevent psychological confusion. Tourists can also register as an ordinary member of the system, so they have the right to publish the training of on-site information, psychology and psychological counseling skills. When they have enough knowledge and good character and are satisfied to become a peer psychological counselor, they will be manually operated by the system administrator to 
Article History: Received: 28 October 2021 Revised: 05 December 2021 Accepted: 10 January 2022 Publication: 28 February 2022

become a peer psychological counselor. When there are a certain number of peer psychological counselors, the system is perfect. It can comprehensively use the communication with college students' peer psychological counselors, music counseling module and reading module to solve students with psychological confusion in the most acceptable way.

\section{REALIZATION OF MAIN FUNCTIONS OF THE SYSTEM}

\section{User registration}

The system takes Dreamweaver as the development tool, adopts ASP technology, script language JavaScript and VBScript. B / S architecture is the operation mode of the system. The running environment for providing services for the web is Windows Server $2008+$ IIS7. Users can use this system in various operating systems such as Windows XP, win7 and win8.

(1) Function introduction. User registration is a module convenient for website management. Users become members of the system through registration and can carry out activities with relevant permissions only after they pass identity authentication when logging in. Only by registering as an ordinary member of the system can they have the right to upgrade to a peer psychological counselor.

(2) Run the process. This module is designed with B / S architecture. User browsing is the foreground interface, and ASP is the development language of application layer to connect the front-end and background database layer for business and data exchange.

(3) Data sheet design. The system needs to store member information, including user name, password, name, age, major, grade, etc. Only one data table is needed. The member data table is called member, as shown in Table 2.

TABLE II. Membership form

\begin{tabular}{|c|c|c|c|c|}
\hline NAME & $\begin{array}{c}\text { DATA } \\
\text { TYPE }\end{array}$ & LENGTH & $\begin{array}{c}\text { ALLOW } \\
\text { NULL }\end{array}$ & EFFECT \\
\hline ID & Auto number & Long integer & No & Member number \\
\hline username & Text & 50 & No & Member name \\
\hline psw & Text & 16 & No & Member password \\
\hline cname & Text & 20 & Yes & Member's real name \\
\hline sex & Text & 4 & Yes & Member gender \\
\hline email & Text & 50 & Yes & Member email \\
\hline addtime & Text & 50 & No & Member registration time \\
\hline memtype & Text & 20 & No & Membership level \\
\hline
\end{tabular}


Article History: Received: 28 October 2021 Revised: 05 December 2021 Accepted: 10 January 2022 Publication: 28 February 2022
fenshu
Text
20
Yes
Member assessment results

\section{Peer chat room}

(1) Function introduction. The establishment of peer chat room overcomes the shortcomings of traditional counseling methods, gives full play to the advantages of the network, and timely realizes the interaction between helpers and peer counselors. It is the core of College Students' psychological counseling support system. Because psychological counseling involves personal privacy, the counseling records are confidential, which makes this module different from other ordinary chat rooms. It is a one-to-one counseling.

(2) Run the process. After logging in, members can enter the peer psychological counseling module, select corresponding peer counselors and communicate with them. As shown in Figure 1.

(3) Database design. The design of the chat room has three tables, one is the information table (MSG), the other is the reply table (msgreplys), and the user information table.

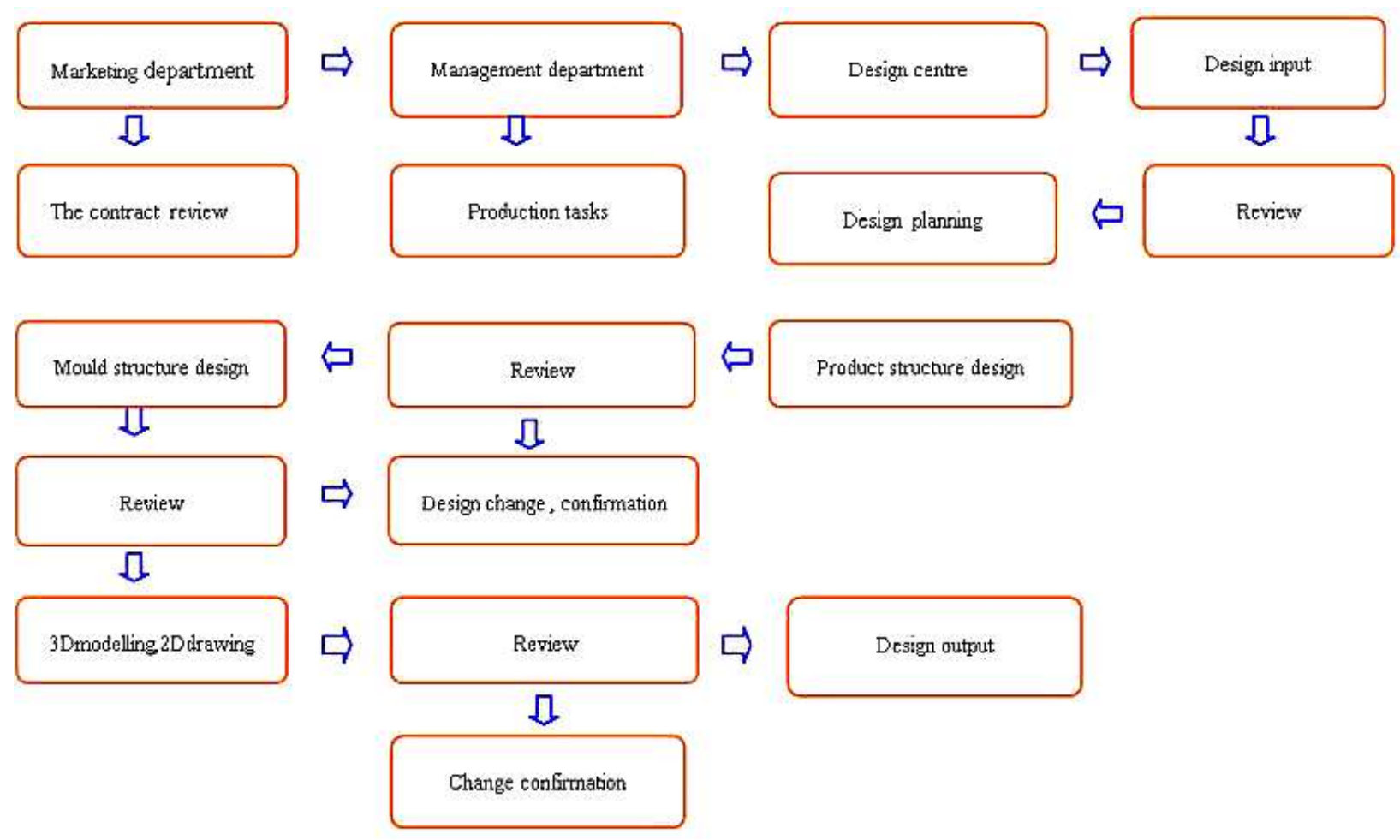

Fig 1: Operation flow chart of peer chat room

3.Psychological test

(1) Function introduction. In psychological counseling, diagnosis is used to find the 
Article History: Received: 28 October 2021 Revised: 05 December 2021 Accepted: 10 January 2022 Publication: 28 February 2022

personality defects of visitors as part of the basis for personality remodeling, and can also be used to find the psychological health status of visitors as the basis for psychological adjustment. At the same time, intelligence test and ability tendency test can be used as career guidance tools. Because one of the conditions for success in finding a suitable career is that one's career is suitable for one's own ability. Various occupations need different intelligence. Therefore, in addition to interests, volunteers and other conditions, employment guidance also needs to carry out intelligence and ability tendency tests to determine which occupations they are suitable for.

(2) Run the process. The process of psychological test is that users select test items, then submit their selected answers, and then the system gives a test result for users' reference.

(3) Test implementation. Its is to display and set test questions. When the user answers the questions, a score will be fed back, and the possible state corresponding to the score segment will be presented for the user's reference.

\section{MAIN FUNCTION TEST AND PRELIMINARY APPLICATION OF THE SYSTEM}

\section{System function test}

System function test is a comprehensive test of the system to judge whether it meets the requirements of demand analysis and whether there are defects. After finding the problems, correct them, improve the performance of the system, improve the system functions, and ensure the reliable and smooth operation of the system.

User registration is used to test the security of the system and determine whether the same account can be registered again. After applying for an account ceshi for the test content, apply for an account ceshi again.

The function of random topic selection is to make the questions drawn by the students tested again different, so as to prevent the students from only remembering dozens of questions to meet the upgrade conditions. Of course, it also requires that no less than 200 questions be added in the background of topic selection. In this way, the repetition rate of randomly selected test questions will be very low, so as to reduce the repetition rate. The test content is randomly selected twice to judge the detection repetition rate. The test condition is that there are 50 questions in the question bank. Each time, 10 questions are selected twice. Compare the repetition rate of the two selected questions. The test content is randomly tested for the first time. The test results show that there are no duplicate questions in the content randomly selected twice, so the function of randomly selected questions is relatively perfect, which can effectively avoid the same students drawing the same questions when they repeatedly draw the questions.

Psychological evaluation system is a computerized evaluation tool used by professional psychological counselors to do psychological evaluation. The psychological evaluation system includes international standard test scales, which are widely used in psychological counseling, 
Article History: Received: 28 October 2021 Revised: 05 December 2021 Accepted: 10 January 2022 Publication: 28 February 2022

intelligence evaluation, career selection and matching, marriage and love evaluation, personality test and various psychological tests. Psychological evaluation can not only be used to evaluate people's thinking, emotion, behavior, interpersonal relationship, living habits, sleep and so on. Psychological evaluation is like a mirror and a lighthouse. It can not only let the tester understand himself, but also remind the tester of self-cultivation at any time, so as to help the tester find a way of counseling.

\section{Application examples}

Caller a: gender, female, age 20, sophomore year. Family conditions are not good. I have lived with my grandmother since childhood. My Mandarin is poor, but my grades are good, but I dare not participate in any community activities. I am very eager to communicate with others and hope to have good interpersonal relations like other students.

The following is a consultation conversation between college student peer counselor and caller a:

Caller a: I get nervous when I talk to others. What do you say?

College peer counselor: can you tell me what you are nervous about? Or what are you afraid of?

Caller a: because I was with grandma since childhood, our dialect is heavier.

College peer counselor: do you think this is a problem?

Caller a: it's a big problem. I grew up in the countryside. They can't understand me when talking to them. They also need to translate. There are few people who want to talk to me.

College student peer counselor: This is not a big problem. There are many associations in our school. The students in the associations will teach you Mandarin enthusiastically. You just need to overcome the psychological pressure and practice more. It should be no problem.

Caller a: but I dare not.

College peer counselor: why?

Caller a: I'm afraid they will be like my roommates and classmates. They don't want to talk to me anymore.

College student peer counselor: another way is that I teach you. Don't worry, I won't ignore you because your Mandarin is not good.

Caller a: really?

In this case, the peer psychological counselor of college students can't get the response of caller a in the process of guidance, and the caller with low self-esteem is closing his heart. However, the college students' peer psychological counselors did not point out that they taught the helpers to learn Mandarin, which fully reflected the college students' peer psychological counselors' due love and quasi professional skills, and solved the problems of the helpers.

\section{CONCLUSION}


Article History: Received: 28 October 2021 Revised: 05 December 2021 Accepted: 10 January 2022 Publication: 28 February 2022

Aiming at the general psychological problems encountered by college students in campus learning and life, this paper develops a college students' psychological counseling support system based on peer psychological counseling theory and web technology. The system adopts one-stop counseling mode, so that college students can dredge psychological problems according to the mode of "psychological test - Music counseling - reading counseling communication with peer psychological counselors". At the same time, college students can also use the system according to their own ideas. They can browse the music counseling and reading counseling module of the system without even registering an account to solve their own psychological problems.

\section{REFERENCES}

[1] Wei Xu. (2014). Enrich college English teacher's knowledge of summarizing strategies instruction and expository text comprehension with kirsch's reading model. Coronary Artery Disease, 17(4), 331-7.

[2] Dorr, L. J., (1988). A nineteenth century botanical text-book in the malagasy language. Archives of Natural History, 15(2), 171-183.

[3] Trilok Chandra Goel, Apul Goel, \& Sandeep Kumar. (2018). My tryst of writing and publishing a comprehensive medical textbook in vernacular hindi and new hindi medical terminology. Indian Journal of Surgery, 80(2), 1-6.

[4] Ullrich, C., Shen, R., Tong, R., \& Tan, X., (2010). A mobile live video learning system for largescale learning-system design and evaluation. IEEE Transactions on Learning Technologies, 3(1), 617.

[5] Zhang, Y. X. , Feng, Y. X. , \& Yang, R. Q. . (2019). Network public opinion propagation model based on the influence of media and interpersonal communication. International Journal of Modern Physics B, 1950393.

[6] Feng, Z. . (2018). Hot news mining and public opinion guidance analysis based on sentiment computing in network social media. Personal and Ubiquitous Computing, 23(3-4), 373-381.

[7] Xia, P. , \& Zhou, H. . (2017). A novel popular tourist attraction discovering approach based on geotagged social media big data. ISPRS International Journal of Geo-Information, 6(7), 216.

[8] Neville, M. C. , Keller, R. , Seacat, J., Lutes, V., Neifert, M. , \& Casey, C. , et al. (1988). Studies in human lactation: milk volumes in lactating women during the onset of lactation and full lactation. American Journal of Clinical Nutrition, 48(6), 1375-1386.

[9] Meng Diyun, Wang Yaozhong, Xu Sha. The relationship between network embeddedness, business model innovation and enterprise competitive advantage. Financial theory and practice, 2016, 37(5): 108-114.

[10] Li Xiang, Chen Jixiang. Research on the interaction between technological innovation and business model innovation of new ventures. Modern Management Science, 2015 (3): 109-111. 